\title{
Merger Arbitrage's Performance in Different Regions After Covid-19
}

\author{
Yuran Liang ${ }^{1, \dagger}$, Chenbin Zhang ${ }^{2, *}{ }^{*}$, Lulei Zhang ${ }^{3, \dagger}$ \\ ${ }^{1}$ Finance Department, Jinan University, Guangzhou, China \\ ${ }^{2}$ Accountancy Department, Bentley University, 175 Forest Street, Waltham, MA, 02452, USA \\ ${ }^{3}$ Finance Department, Rutgers, The State University of New Jersey, New Brunswick, USA \\ *Corresponding author. Email: ZHAN3_CHEN@bentley.edu \\ ${ }^{\top}$ These authors contributed equally.
}

\begin{abstract}
Due to different degrees of involvement by governments, Eastern countries have developed distinct financial markets compared to Western financial markets. This article presents the performances of the merger arbitrage strategy in different regional markets, including the United States, Hong Kong, China, Korea, Japan, Mainland China, and Australia. Merger cases after the global outbreak of the Covid-19 were chosen for each region to represent their financial markets. In the analysis, historical data of merger companies' stock prices were analyzed through various charts, capital asset pricing model, and the average excess return regression model. In addition, qualitative factors, including the market constitution, policy distinction, cultural difference, and instability caused by Covid-19, were discussed. Throughout multi-comparisons of both quantitative and qualitative factors, we found out that Hong Kong's and American markets are the best markets for investors to apply merger arbitrage strategy. For institutional and individual hedge fund investors, our conclusion will be able to contribute to improving the yield rates of the merger arbitrage strategy.
\end{abstract}

Keywords: Merger Arbitrage Performance, Hedge Fund Strategy, Different regions, Global, after Covid-19

\section{INTRODUCTION}

Among all the popular hedge fund strategies nowadays, merger arbitrage is one of the most special kinds. With the merger arbitrage strategy, investors usually long and short respective companies' stocks, which are in the process of merger or acquisition. Since the target company's stock usually sells below the price offered by the bidder company, once the merger has been completed, stockholders will be making "risk-free" profits. Unlike the market risk that investors are familiar with in using other hedge fund strategies, merger arbitrage is mainly about event risk, which is when the merger is not completed [1]. In other words, merger arbitrage is special and important for its avoidance of market risk.

Speaking of the historical importance of merger arbitrage, according to the book Merger Arbitrage by Thomas, in the late 1960s, it gave rise to growing interests in merger arbitrage. This investing strategy coincided with a wave of aggressive merger activity in England and the United States [1]. Before the year of 2003, merger arbitrage investing mainly concentrated in the western country, while no activities at all had taken place in key East Asian markets, such as India, Indonesia, and Korea [2]. Starting from the year 2003, things have changed a lot: from research by Eurekahedge, a hedge fund consultancy, approximately 200 million USD per month is flowing into Asian markets from the US, and a total of 1 billion USD per month going into Asian funds in 2003. With so much money flowing into Asian funds, the financial system has been gradually established.

In the beginning, it's easy to see that Asian funds were only replicas of western counterparts at the beginning of the $21^{\text {st }}$ century [2]. However, due to Asian different ideologies, many unique regulations and policies have been gradually set up since then. Nowadays, the financial system in Asia has been quite different from what it is in the western right now. Take Mainland China as an example, investors cannot short stocks in Mainland China's stock market, so merger arbitrage applied in China's market will be quite different since investors can only make long-side trade. Thus, in this article, our purpose is to analyze outcomes of merger arbitrage strategy in different markets, and our findings will 
improve global investors' understanding of merger arbitrage's application.

\section{DATA/METHODOLOGY}

This section reveals our approach to measure the profitability of a merger arbitrage strategy. Bali et al. (2012) demonstrated a comprehensive measure of systematic risk (SR) for individual hedge funds by breaking up total risk into systematic and residual risk components [3]. From the international review of financial analysis, Ben Branch claimed that risk arbitrage for stock swaps involves holding a long position in the target firm's stocks and a short position in the acquiring firm's stocks at the same time to hedge the risks [4]. So, we took the spread of the long-short trade and standard deviation of return rates from investing in different regional markets into the portfolio risk measurement. As French, K.R examined the close relationship between stock returns and stock market volatility, the Sharpe ratio considers the influence of both excess return and volatility on the whole merger arbitrage, so we will use this ratio to make a direct numerical comparison in the analysis [5].

We selected representative enterprise merger cases in different countries and regions and then obtained more detailed data such as daily prices through Wind Database. Using the excess return rate of 10 -year treasury bonds as the benchmark, which is the market return (average return), we generate the excess return rate of each merger arbitrage. Moreover, the stock trend chart of Target Company and Bidder Company during their merger period is made to present an intuitive horizontal comparison.

Along the way, we are still using the Stocktrak, a simulated global stock trading platform, to keep track of stock price changes, latest news, and market sentiment in different merger cases to produce a comprehensive, objective, and detailed analysis.

\subsection{Excess return rate}

The stock return rate is the index that reflects the stock return level. Investors care about the most when buying stocks or bonds is how much profits they can gain from the trading. The yield rate is used to measure the profits gained from a security investment. People generally use the daily rate of return, the monthly rate of return, and annual stock yield to measure the rate of return of a single stock. To conduct a more detailed case analysis, obtaining the daily yield returns of individual stocks is obviously a better choice. In addition, the average market return yield can be reflected by the representative stock market index fund,

Daily stock yield $=$ (price of the day - price of the day before)/price of the day before
Daily index yield $=($ current day index - previous day index)/previous day index

The excess return rate is the rate of return that exceeds the normal (or expected) return rate, which is equal to the actual return rate on a certain day minus the normal (expected) return rate required by investors (or the market) that day. In this paper, to facilitate the horizontal comparison and analysis of profit of different merger arbitrage, we collected historical return rates upon regional 10-year treasury bonds. For example, we collected return rates upon China's 10-year treasury bond, and we calculated the average of them as the market return rate in China's case analysis since this is the riskfree return rate for investors in China's stock market.

Excess return $=$ daily stock return - daily 10-year treasury bond return

Portfolio return $=$ long excess return + short excess return

\subsection{Sharpe Ratio}

Sharpe Ratio is a performance indicator describing a fund. The Sharpe index reflects the degree to which the net growth rate of a venture fund exceeds the risk-free return rate. The Sharp index means that investors can get a few points more than the risk-free rate of return (deposit rate) for every extra risk they take. If it is positive, it means that the fund has a positive return on the risk of return rate fluctuation; If it is negative, it means that the return is less than the risk-free return from the bank. Sharpe index calculation is as follows:

Sharpe index $=$ [average return - risk-free return] / standard deviation.

After calculation, we figure out the risk-free rate, excess return, and Sharpe Ratio of each regional case as below:

Table 1. Ratios of regional cases.

\begin{tabular}{lccc}
\hline Market & $\begin{array}{c}\text { Risk-free } \\
\text { Rate(\%) }\end{array}$ & $\begin{array}{c}\text { Portfolio } \\
\text { Excess } \\
\text { Return(\%) }\end{array}$ & $\begin{array}{l}\text { Sharpe } \\
\text { Ratio }\end{array}$ \\
\hline The U.S. & 1.297 & 39.18 & 9.050 \\
Hongkong & 1.028 & 10.01 & 2.416 \\
Korea & 1.690 & -48.02 & -0.497 \\
Japan & 0.023 & 0.350 & -1.683 \\
China & 2.867 & 42.40 & 22.658 \\
Australia & 1.230 & 30.94 & 8.141 \\
\hline
\end{tabular}




\section{EMPIRICAL DISCUSSION}

Quantitative Case Analysis and Qualitative Factor Analysis are included in this section.

In quantitative case analysis, 6 merger cases were chosen from different countries after the global outbreak of the Covid-19. Their stock prices were analyzed through charts, and yield returns will be discussed upon applying merger arbitrage in each case.

In qualitative factor analysis, factors like the financial system, political system, cultural value, and other uncertainty during the Covid-19 were discussed.

\subsection{Quantitative Case Analysis}

This section chose 6 representative merger cases, including cases in the US, Hong Kong, China, Korea, Japan, Mainland China, and Australia. Both bidder companies and target companies' headquarters are located in the same region, which means no foreign exchange control in our selected cases. In other words, the cases below should only reflect the situation of one financial market.

Also, all these 6 mergers happened around the global outbreak of Covid-19. Thus, they all reflect a typical country's financial market at the same point.

\subsubsection{The U.S}

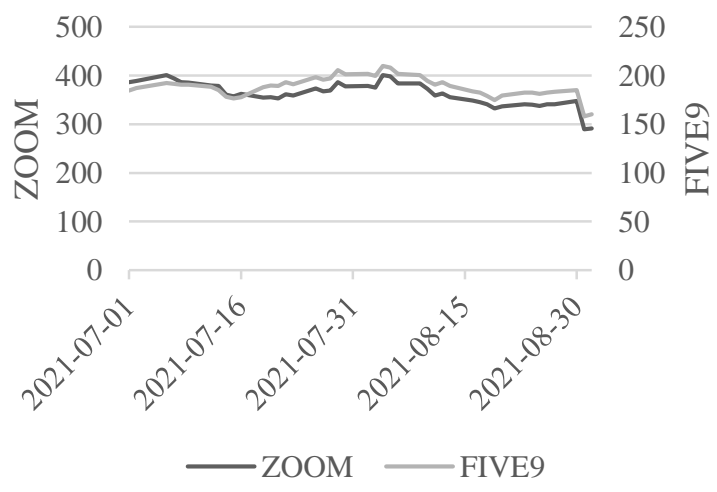

Figure 1. The daily stock price of Zoom and Five9

In July 2021, the CEO of Zoom announced the acquisition of Five9, a cloud computing provider, at the price of 14.7 billion dollars. From Zoom's CEO's Blog, this acquisition is expected to close in the first half of the calendar year 2022 [6].

After the outbreak of the Covid-19, Zoom achieved explosive growth. Till now, many enterprises and schools have been using zoom to hold classes and meetings. With the rapid growth of its customer base, acquiring a cloud reinforces Zoom's competency in the industry and allows Zoom to add more functions to the platform.
Figure 1 indicates the movements of their stock prices after the announcement of the acquisition. From Table 1, if we apply merger arbitrage from the announcement date, the excess portfolio return till now can be $39.18 \%$.

\subsubsection{China (HK)}

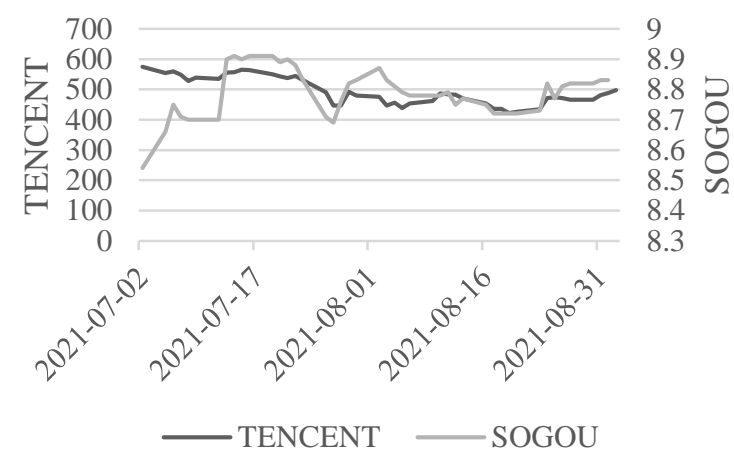

Figure 2. The daily stock price of Tencent and Sogou

In July 2021, the Anti-Monopoly Bureau of China unconditionally approved the acquisition between Tencent and Sogou for $\$ 9$ per share [7]. As the biggest internet company in China, Tencent's complete coverage of its products chain is always a goal. Sogou is famous for its input editor and searching platform. Such acquisition is a strategic step for Tencent to accomplish the complete coverage of its products.

Figure 2 presents the movements of stock prices of Tencent and Sogou after the approval of the acquisition. From Table 1, by applying merger arbitrage strategy from the date of approval, the excess portfolio return can be $10.01 \%$ till now.

\subsection{3. $\quad$ Korea}

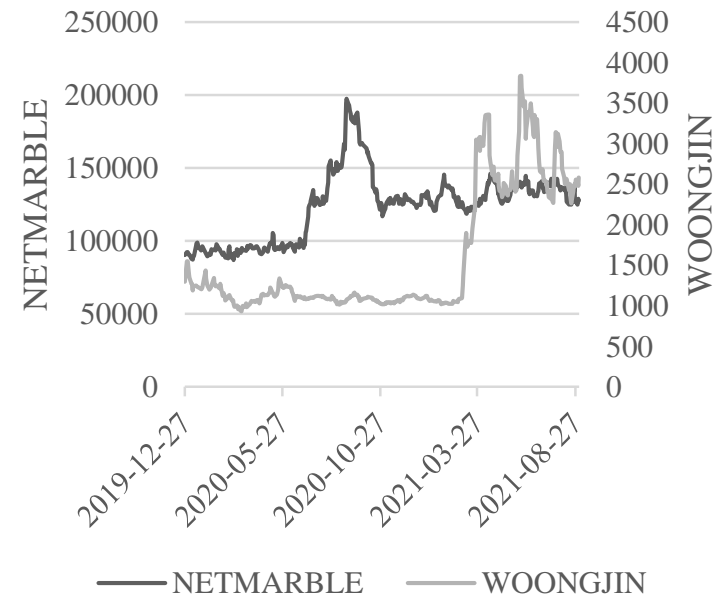

Figure 3. The daily stock price of Netmarble and Woongjin 
At the end of 2019, the CEO of Netmarble Games Corp announced the plan to acquire Woongjin Coway, which is a water purifier leasing company in South Korea.

During the spread of the epidemic, many companies with a single business have been facing tremendous pressure. To hedge risks, diversity of business is key to success in the future. Netmarble Games Corp, South Korea's largest mobile game company, was expected to diversify the enterprise and remain competitive in the market through this acquisition.

Figure 3 indicates the movements of their stock prices after the announcement of their acquisition. From Table 1 , if merger arbitrage is applied in this acquisition, the excess return rate will be $-48.02 \%$.

\subsubsection{Japan}
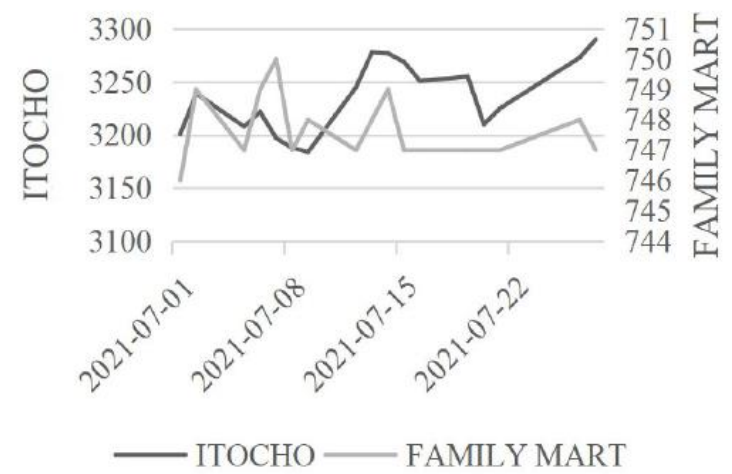

Figure 4. The daily stock price of Itochu and Family Mart

In July 2021, Itochu announced the acquisition of Family Mart at the price of 2300 Japanese Yen a share.

Itochu was found in the $1858 \mathrm{~s}$, starting from the business of linens. Until the first half year of 2021, Itochu's business covers various industries, including metals, mechanics, communication, petroleum, etc. The Family Mart is one of the biggest retailers in Japan, with about 16,500 stores in Asia [8]. With family mart's abundant customer basis, Itochu can further improve its influence in Asia.

From figure 4, we can see the movements of Itochu and Family marts' stock prices after the announcement of this acquisition. From Table 1, if we apply merger arbitrage in this acquisition, the excess return rate can be $0.35 \%$

\subsubsection{China (Mainland)}

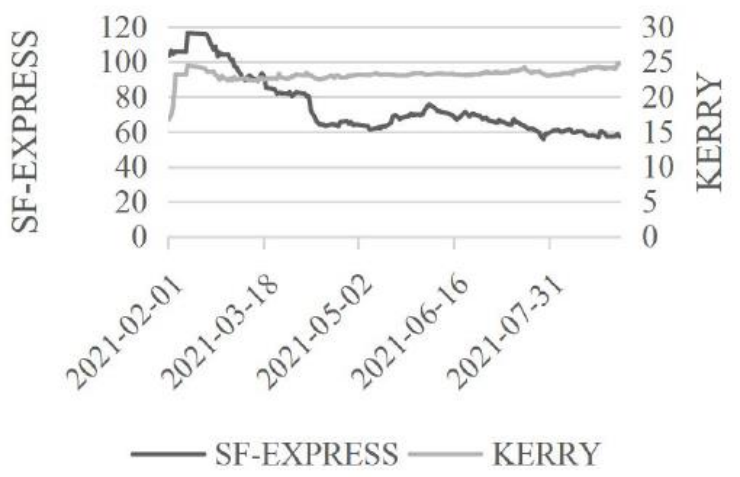

Figure 5. The daily stock price of SF-express and Kerry

In February 2021, SF holdings announced that it planned to acquire $51.8 \%$ equity of Kerry Logistics by the partial tender offer.

Regarding the background of the acquisition, SF is one of the biggest companies that provide express service in China, and it is trying to transform into an integrated logistics service provider. After the acquisition of Kerry Logistics, which provide express and logistics service in Asia, SF will be able to provide service, such as express, cold transport, intracity distribution globally at the lower costs.

Figure 5 presents the movements of SF Express and Kerry Logistics' stock prices after the announcement of this acquisition in February 2021. From Table 1, the excess return rate upon applying merger arbitrage, in this case, is $42.4 \%$.

\subsubsection{Australia}

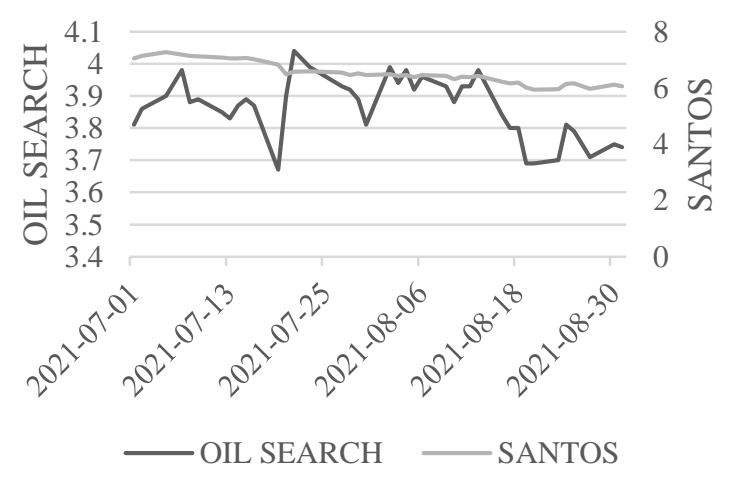

Figure 6. The daily stock price of Santos and Oil Search

In July 2021, Santos announced at the release upon a possible merger between Oil Search and Santos [9], and a few weeks later, Santos updated the confirmation upon the merger with Oil Search by uploading the agreement upon proposed merger ratio with Oil Search [10].

The merger proposal indicates that this merger will be implemented through stock exchanges. Specifically, Oil 
Search shareholders will receive 0.589 new Santos shares for each Oil Search share held. Following such a scheme, Santos shareholders would own nearly $63 \%$ of the merged company, while Oil Search shareholders would own the rest of $37 \%$. Given Santo's closing price on 24 June 2021, the transaction price for Oil Search would be 4.25 Australian dollars per share. [9].

Figure 6 indicates the stock prices of Santos and Oil Search after the announcement of a possible merger. If we apply the merger arbitrage strategy from announcing their possible merger back in July, our portfolio's excess return can be $30.94 \%$.

\subsection{Factors Analysis}

In different regions, factors such as financial markets, regulation policies, and cultural values always lead to different results of investing behavior. After decades of development, different financial systems have been formed in different regions. Moreover, an unexpected crisis like Covid-19 also deepens the uncertainty of investing in different markets.

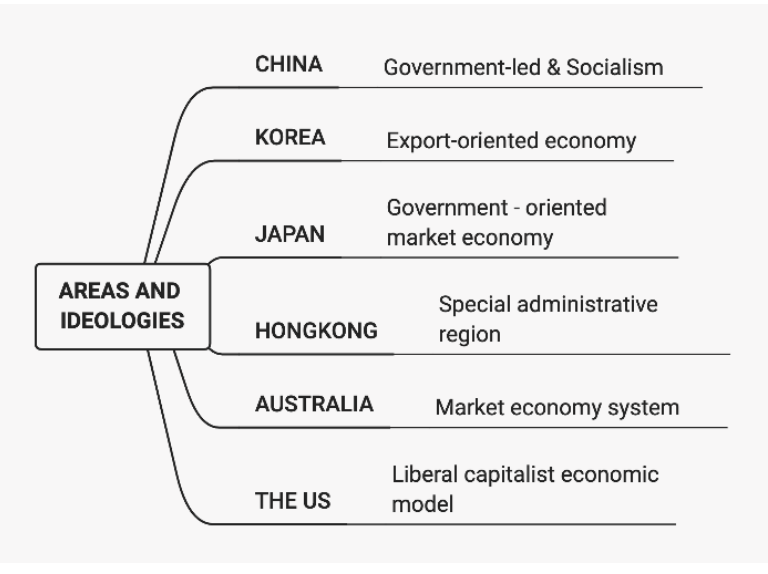

Figure 7. Ideologies of different regions

Figure 7 indicates the different ideologies for all 6 countries in the quantitative analysis. The difference between their ideologies determined their financial markets' developments.

Western and eastern finance are in different stages of development. The United States, as the most representative western country, is in an advanced stage of market development, which can be embodied in its large market scale, abundant financial tools, and strong capital energy. The same goes for Japan. After World War II, Japan imitated the American financial market and spent 40 years becoming the most developed financial market in Asia. In addition, Hongkong and Australia's financial markets are inevitable to talk about. Since establishing the first stock exchange in 1891, Hong Kong's financial market has developed for more than 90 years. During the British colonial period, the financial market of Hong Kong was stimulated by the British government, which made Hong Kong the financial center in Southeast Asia.
Also, as the second-largest stock market in Asia besides Japan, Australia's financial position cannot be ignored. In contrast, regions like Korea and Mainland China are in the initial stage in terms of financial market development, which can be manifested by their small market scale, unreasonable structure, and few financial tools. This difference limits the returns upon applying merger arbitrage in their markets.

At the same time, the openness of financial markets in the east and the west is different. The American financial market is fully open, and it is the largest global market in the world. Investors in the American financial market can exploit global resources and pricing power all over the world. In contrast, the financial market in the East is relatively closed, which is reflected in the difficulty in making effective use of global resources and the lack of global pricing power and influence. Take Japan, Korea, Mainland China, and Australia as examples. Although some of them have developed financial markets, their financial markets are totally under governments' regulations. Take China as an example. At the beginning of September, the Ministry of education of China releases a document forbidding after-school training programs. As a result, educational stocks like New Oriental, and Xue, dropped by more than $80 \%$ of their original stock prices. In addition, a few months ago, the Chinese government carried out the antimonopoly law upon internet companies. Leading companies like Tencent and Alibaba dropped by more than $10 \%$ within 1 week. The same goes for real estate, medical, and many other industries. It's easy to see that countries like China are still in the process of reforming, where governments tend to put everything under control.

There are also areas in Asia where the financial market is fully open, and Hong Kong is one of them. As the only special administrative region in China, the financial market in Hong Kong is quite different from that in Mainland China. Similar to regulation in the western countries, the Hong Kong regional government's principle of non-intervention upon the operation of the financial market has provided investors with an efficient and free environment. Meanwhile, Hong Kong's geographical location has special meanings for investing. First, Hong Kong is an important hub for economic and commercial activities in East Asia. Also, the opening of Hong Kong's stock market is ingenious. It's opening after the closing of the New York market and closing in front of Europe's stock market's opening. In other words, Hong Kong's stock market fills the gap between Europe and America in a day and is an important station for global investing.

During the Covid-19 epidemic, mergers and acquisitions usually faced more uncertainty. First, mergers during the Covid-19 faced more hinders than they used to do. During the Covid-19, it became harder for the bidder company to complete on-site due diligence 
upon the target company, which made the merger riskier. Moreover, such an obstacle might prevent both companies from reaching an agreement upon the value assessment of the target company. In addition, some documents assess the risk level upon the merger or acquisition. For example, the standardized transaction term like "Material Adverse Change (MAC)" is one of them. However, it is difficult to assess risks brought by Covid-19 upon the merger or acquisition. For those companies that have been in the middle of the merger process, many bidder companies have paused the merger process, claiming that the epidemic brought up huge risks to the company. Thus, the uncertainty of merger cases under the Covid-19 is more controversial.

So, how should we recognize the reliable merger or acquisition transactions under the epidemic, whether they are risks or opportunities? Right now, most countries still take M\&A as their strategies to stimulate the economy in the next two years. Although merger or acquisition is not the only key factor to achieve growth, it is an important strategy for economic recovery. Here, take the United States and China, which are the most representative of the East and the West and developed and developing countries, as examples. In the economic downturn of the United States, M\&A is one of the most important and effective means of asset expansion for companies. Large companies in the United States need to seek their development and obtain high profits through M\&A to drive economic development. This is the inevitable result of the highly developed market economy. However, in China, the motivation of M\&A is to eliminate unprofitable sectors. Since China's economic resource allocation is unreasonable and inefficient, it is unrealistic to rely on enterprises' self-adjustment to recover during the economic recession. Thus, under such an epidemic period, government regulation became necessary in Asian countries, and investing in M\&A cases in Asia became riskier, although the returns seemed attractive.

\section{CONCLUSION}

Upon both our quantitative and qualitative analyses above, we found huge differences between financial markets in different regions.

Speaking of the excess return, merger arbitrage performs the best in Mainland China, United States, Australia, and Hong Kong's markets with 42.4 per cent, 39.18 per cent, 30.94 per cent, and 10.01 per cent portfolio excess return.

Due to different ideologies, regions like Hong Kong, China, and the United States advocated the "invisible hand" to build a free market, where they believe that the economy would adjust by itself. Thus, there was less regulation restricting investors' strategies in the market. In contrast, other regions like Korea, Japan, Mainland China, and Australia preferred to put everything under control. For example, investors can only long stocks in
Mainland China, which has a huge influence on the application of merger arbitrage. However, the Hong Kong market, due to the policy, is under its control rather than the mainland's policy.

Given our observation and analysis above, from all 6 regions, including the US, Hong Kong, China, Korea, Japan, Mainland China, and Australia, we strongly recommend applying merger arbitrage strategy in the American and Hong Kong markets for both quantitative and qualitative reasons.

Admittedly, our research method applied in this article still needs improvement. Specifically, using one merger case to represent the entire financial market in one region is not prudent. In the following research, we will try to narrow down our research range and improve the depth instead.

\section{REFERENCES}

[1] Thomas, K. Merger arbitrage, 2nd Edition. Wiley, 2016, pp.1-17.

[2] Robertson, J. Replica localization in East Asia: the case of the Asian hedge fund industry. Globalizations, 2018, vol. 15, pp. 407-421. DOI: https://doi.org/10.1080/14747731.2018.1424286

[3] Bali, T.G., Brown, S.J., Caglayan, M.O. Systematic risk and the cross section of hedge fund returns. Journal Financial Economics, 2012, vol. 106, pp. 114-131.

DOI: https://doi.org/10.1016/j.jfineco.2012.05.005

[4] Ben, B., Taewon, Y., A test of risk arbitrage profitability, International Review of Financial Analysis, 2006, vol. 15, pp. 39-56. DOI: https://doi.org/10.1016/j.jfineco.2012.05.00510.101 6/j.irfa.2005.08.001

[5] French, K.R., Schwert, G.W., Stambaugh, R.F. Expected stock returns and volatility, Journal of Financial Economics, 1987, vol. 19, pp. 3-29. DOI: https://doi.org/10.1016/j.jfineco.2012.05.00510.101 6/0304-405X(87)90026-2

[6] Eric, S. Yuan, Zoom to acquire Five 9 and build the customer engagement platform of the future, July 18, 2021. Available at: https://blog.zoom.us/zoom-toacquire-five9/

[7] Anti-Monopoly Bureau of China, List of unconditional approval of merger cases, July 13, 2021. Available at: http://www.samr.gov.cn/fldj/ajgs/wtjjzajgs/202107/t 20210713_332601.html

[8] Moody's, ITOCHU takeover of family mart is credit negative, not ratings impact, July 9, 2020. Available at: 
https://finance.yahoo.com/news/itochu-corporationmoodys-itochus-takeover-053417332.html

[9] Santos, Santos confirms oil search merger proposal, July 20, 2021. Available at: https://www.santos.com/news/santos-confirms-oilsearch-merger-proposal/

[10] Santos, Santos agrees proposed merger ratio with oil search, August 2, 2021. Available at: https://www.santos.com/news/santos-agrees-

proposed-merger-ratio-with-oil-search/ 